\title{
Natural polymorphisms and unusual mutations in HIV-1 protease with potential antiretroviral resistance: a bioinformatic analysis
}

\author{
Carlos Mata-Munguía', Martha Escoto-Delgadillo2,6, Blanca Torres-Mendoza 2,7, Mario Flores-Soto 2,8 \\ Mildred Vázquez-Torres ${ }^{2}$, Francisco Gálvez-Gastelum³ ${ }^{3}$ Arturo Viniegra-Osorio ${ }^{4}$, Marcelo Castillero-Manzano ${ }^{5}$ \\ and Eduardo Vázquez-Valls $s^{2,5^{*}}$
}

\begin{abstract}
Background: The correlations of genotypic and phenotypic tests with treatment, clinical history and the significance of mutations in viruses of HIV-infected patients are used to establish resistance mutations to protease inhibitors (PIs). Emerging mutations in human immunodeficiency virus type 1 (HIV-1) protease confer resistance to Pls by inducing structural changes at the ligand interaction site. The aim of this study was to establish an in silico structural relationship between natural HIV-1 polymorphisms and unusual HIV-1 mutations that confer resistance to Pls.

Results: Protease sequences isolated from 151 Mexican HIV-1 patients that were naïve to, or subjected to antiretroviral therapy, were examined. We identified 41 unrelated resistance mutations with a prevalence greater than $1 \%$. Among these mutations, nine exhibited positive selection, three were natural polymorphisms $(L 63 S N / H)$ in a codon associated with drug resistance, and six were unusual mutations (L5F, D29V, L63R/G, P79L and T91V). The D29V mutation, with a prevalence of $1.32 \%$ in the studied population, was only found in patients treated with antiretroviral drugs. Using in silico modelling, we observed that D29V formed unstable protease complexes when were docked with lopinavir, saquinavir, darunavir, tipranavir, indinavir and atazanavir.

Conclusions: The structural correlation of natural polymorphisms and unusual mutations with drug resistance is useful for the identification of HIV-1 variants with potential resistance to Pls. The D29V mutation likely confers a selection advantage in viruses; however, in silico, presence of this mutation results in unstable enzyme/PI complexes, that possibly induce resistance to Pls.
\end{abstract}

Keywords: Antiretroviral agents, Bioinformatics, Molecular docking simulation, Drug resistance, HIV protease, In silico, Polymorphism, Mutations

\section{Background}

Diversity of viral populations is a result of sophisticated recombination, replication and/or selection events that induce drug-resistant human immunodeficiency virus type 1 (HIV-1) variants. The lack of reverse transcription corrections, transitional printing and transversion mutations, along with viral recombination, has resulted in the

\footnotetext{
*Correspondence: eduardo.vazquez@imss.gob.mx

${ }^{2}$ Laboratorio de Inmunodeficiencias y Retrovirus Humanos, Centro de Investigación Biomédica de Occidente, CMNO, IMSS, Guadalajara 44340, México

${ }^{5}$ UMAE, Hospital de Especialidades, CMNO, IMSS, Guadalajara 44340, México Full list of author information is available at the end of the article
}

emergence of HIV-1 variants with high resistance to pharmacological stressors [1,2]. These variants form populations that evade antiretroviral agents, due to emerging phenotypic changes within and around the active enzyme site [3]. These mutations, which give rise to drug resistance, result in reduced efficacy of highly active antiretroviral therapy (HAART) [4]. Correlations between genotypic and phenotypic tests with treatment, clinical history, and significance of mutations identified in HIV-1 of infected patients are used to determine the presence of mutations that confer resistance to protease inhibitors (PIs) [1].

\section{Biomed Central}

(c) 2014 Mata-Munguía et al.; licensee BioMed Central Ltd. This is an Open Access article distributed under the terms of the Creative Commons Attribution License (http://creativecommons.org/licenses/by/2.0), which permits unrestricted use, distribution, and reproduction in any medium, provided the original work is properly credited. 
Disruption at interaction sites causes an alteration in affinity between proteins and their inhibitors, and has been recognized as a property of drug resistant HIV-1 proteins $[5,6]$. Protein folding simulation models can create Local Elementary Structures (LES). These secondary structures are stabilized by amino acids that interact with the polypeptide chain [7]. Using the Gromacs software (version 3.0), LES were found to form in protease (PR) regions 23-33, 74-78, and 83-92, and also docked in a folding nucleus [8]. Other studies have shown that mutations further from the active site can alter the flexibility of HIV-1 PR, inducing structural changes that affect the efficacy of most PIs currently used [9]. Theoretical studies, either alone or in combination with experimental methods, have pointed to an increase in the flexibility of mutant enzymes at various sites, including the active site, as a resistance mechanism that causes a decrease in the affinity of PIs [10]. Part of the cause of such flexibility could be the unusual mutations that generally emerge only after "major" and "minor" resistance mutations have been introduced [11]. Other mutations that can affect the interaction between PR and PIs are natural polymorphisms and unusual mutations in positions that confer drug resistance. Although the main mutations associated with drug resistance have been characterized $[12,13]$, little is known about the influence of natural polymorphisms and unusual mutations with respect to the development of drug resistance. The aim of this study was to describe an in silico experiment that showed structural correlations between natural HIV-1 polymorphisms and unusual HIV-1mutations in the PR region of HIV-1 pol with potential PIs resistance.

\section{Methods}

\section{Sequence data}

We analysed 151 HIV-1 sequences from Mexican patients who had been tested for resistance to antiretroviral drugs between 2005 and 2011 in the Laboratory of Immunodeficiencies and Human Retroviruses, Western Biomedical Research Center, Mexican Institute of Social Security. Sequences were obtained from 22 naïve, and 129 treated patients that were not responsive to drugs. Sequences were registered in the GenBank database [14], with the following accession numbers: [EU045452EU045489; GU382757-GU382851; GU437199-GU4372 00; and KC416212-KC416227]. All sequences were analysed for the presence or absence of highly mutated sequences using HYPERMUT software (version 2.0) [15]. For a reference sequence, we used the subtype B consensus sequence, which was derived from an alignment of subtype B sequences maintained at the Los Alamos HIV Sequence Database (LANL), and available from the HIV Drug Resistance Database (HIVDB), Stanford University [16].

\section{Phylogenetic analysis}

Nucleotide homology analysis for HIV-1 sequences was conducted using the NCBI Genotyping Tool program [17]. Subtype determinations were further confirmed by phylogenetic analysis performed with the Molecular Evolution Genetics Analysis (MEGA) software package (version 5.0) [18], which includes the recommended reference sequence sets, available from the Los Alamos HIV Sequence Database [19]. Prior to all phylogenetic analyses, HIV-1 pol sequences were aligned using Clustal $\mathrm{X}$ (European Bioinformatics Institute, EMBL) [20]. Sequences with $100 \%$ homology were excluded from the analysis. The nucleotide distance matrix was generated using the Kimura two-parameter Neighbour-joining method [21]. The statistical robustness of the generated trees was verified by bootstrap analysis of 1000 replicates.

\section{Detection of multidrug resistance phenotypes in HIV-1 protease}

The genetic changes associated with drug resistance in viral sequences were established according to HIVdb algorithm version 6.0.9 (http://hivdb.stanford.edu) [22]. The interpretation of drug resistance was performed at various levels of susceptibility for the following USA Food and Drug Administration (FDA)-approved PIs: atazanavir (ATV); darunavir (DRV); amprenavir (APV); indinavir (IDV); lopinavir (LPV); saquinavir (SQV); tipranavir (TPV); nelfinavir (NFV); and ritonavir (RTV). The resistance mutations were classified as major or minor according to HIVdb criteria, or as natural polymorphisms or unusual mutations if they were not associated with resistance [16]. The prevalence $(p)$ for each mutation in the protease region of pol was quantitatively determined as the frequency of the mutation $(M)$ among total sequences evaluated for each position $(N), p=$ $M / N$, using Microsoft Excel 2010. The genetic variation was calculated as the total number of mutations at a nucleotide position divided by the number of evaluated sequences. The Phenotypic Variation (PV) was defined as the percentage (\%) of amino acid substitutions for each position relative to the consensus sequence. For each region, the PV was classified as follows: conserved, $<1 \%$; semi-conserved, 1 to $<5 \%$; variable, 5 to $<10 \%$; and highly variable, $\geq 10 \%$. Values found below the 15th percentile and above the 75th percentile were not considered. Phenotypic mutations with a prevalence of $\geq 1.0 \%$ among 151 amino acid sequences were compared for each PI against the IAS-USA drug resistance mutations list [12]. The structural conservation of PR was defined in a complementary way to that of PV.

\section{Analysis of selective pressure}

The selective pressure and reconstruction of the ancestral state for each PR codon was determined using a maximum likelihood (ML) substitution model and the 
HyPhy algorithm, included in MEGA5 package [23,24]. The synonymous site divergence $(\mathrm{dS})$ and nonsynonymous site divergence $(\mathrm{dN})$ per branch was estimated using the Muse-Gaut codon model [25]. The values of the ML model were estimated from the topology of the phylogenetic tree. The probability of rejecting the hypothesis of neutral evolution was significant with $p \leq 0.05$. The standardized values of $\mathrm{dN}-\mathrm{dS}$ were obtained by the total number of substitutions in the tree (calculated as substitutions expected by site). To distinguish between drug pressure and immune system pressure, results were compared using the HIV positive selection mutation database [26].

\section{Molecular modelling}

Once the natural polymorphisms and unusual mutation codons with positive selection $(\mathrm{dN} / \mathrm{dS}>1)$ and prevalence $>1 \%$ were obtained, homology modelling was used to predict changes in the PR structure. Homology modelling of natural polymorphisms and unusual mutations followed these steps: (i) template selection; (ii) structural alignment; (iii) model construction; and (iv) refinement [27]. To select the template, HIV-1 protease X-ray crystal structure FASTA sequences available from the Protein Data Bank (PDB) [28] and the HIV-1 subtype B consensus sequence available from the HIVdb were aligned using ClustalX [20]. The PR sequence exhibiting greatest identity with HIV-1 subtype B consensus (wild-type template) was chosen as the template for modelling mutant proteases (PRs). The resistant PRs used for reference were modelled with each major PI resistance mutation. Every mutant protein was modelled using a Swiss-Model workspace, which showed the identity (\%). The expected alignment value with the template sequence (E) and the Qualitative Model Energy Analysis (QMEAN4), which estimates the absolute quality model, ranged from $0-1[28,29]$.

\section{Estimation of the free energy of binding}

Using the Autodock/Vina application on a LINUX platform, which had the PyMOL (version 1.4.1) molecular graphics system installed, we estimated the free energy of binding of the complex between mutant PR structures and Pls [30]. Rectangular boxes were used to define the binding sites and these were adjusted by providing specific coordinates of active PR sites before each docking.

Receptor and ligand representations in the Protein Data Bank, Partial Charge \& Atom Type formats (pdbqt) containing atomic charges, atom type definitions and topological information, were produced using Autodock/Vina [30]. To determine if the differences caused by natural polymorphisms and unusual mutations had any effect on the free energy of binding of Pls, the free energy values obtained for the resistant protease/ligand complexes were compared. Natural polymorphisms or unusual mutations with lower or equal affinity to PIs compared with reference proteins containing drug resistance mutations indicate positive resistance. Higher affinity was considered to favour susceptibility of the HIV-1 variant to PIs. The coupled proteases included the wild-type PR [PDB: 1GNO], PRs with major drug-resistance mutations and PRs with natural polymorphisms or unusual mutations at codons having positive selection.

\section{Measurement of distances between protease residues and PIs}

To evaluate the natural polymorphism and unusual mutation atoms that affect the affinity of PIs, we measured the distances $(\AA)$ between the amino acid residue $C_{\alpha^{-}}$ atoms implicated in drug resistance, and the closest heteroatoms of the PIs. Complexes that showed signs of free energy of binding were analysed, suggesting increased drug resistance because of the presence of natural polymorphisms and unusual mutations. Distances were compared with those obtained for the same pair of atoms in the wild-type and resistant PR structures available from the PDB [28]. All interatomic distances were measured with PyMOL (version 1.4.1) [31].

\section{Results and discussion}

\section{Genetic relationships of HIV-1 variants isolated from}

\section{Mexican patients}

Phylogenetic analysis of the 151 HIV-1 protease fragment nucleotide sequences was conducted using a Neighbourjoining tree. Phylogenetic relationships were grouped into the internal nodes of the tree, using subtype B reference sequences [GenBank: U63632 and U21135]. The HIV-1 variants isolated from Mexican patients, and confirmed by analysis with the NCBI Genotyping Tool, were subtype B. This result is consistent with other molecular epidemiology studies of Mexican HIV-1 patients, with or without antiretroviral intervention, where subtype B prevails [32,33].

\section{Drug resistant phenotypes and genotypes of HIV-1 protease}

Non-synonymous genetic changes largely contribute to phenotypic changes [34]. Because of degeneracy in the genetic code, transcription and translation errors during the viral replication cycle, along with functional, structural, pharmacological and immunological selection pressures, there is no absolute mathematical relationship between genetic and phenotypic variations [35]. Variations in the primary structure of the $151 \mathrm{PR}$ sequences are presented in Figure 1. Of the 36 codons associated with major or minor resistance, 19 showed PV $<5 \%$ (L11, L24, D30, V32, L33, E34, K43, I47, G48, I50, F53, D60, G73, T74, L76, N83, I85, N88 and L89). Among these codons, G48, I50 and F53 were present in conserved regions, and L24, D30, L76 and N88 in semi-conserved regions. Six codons (G16, K20, I54, Q58, 


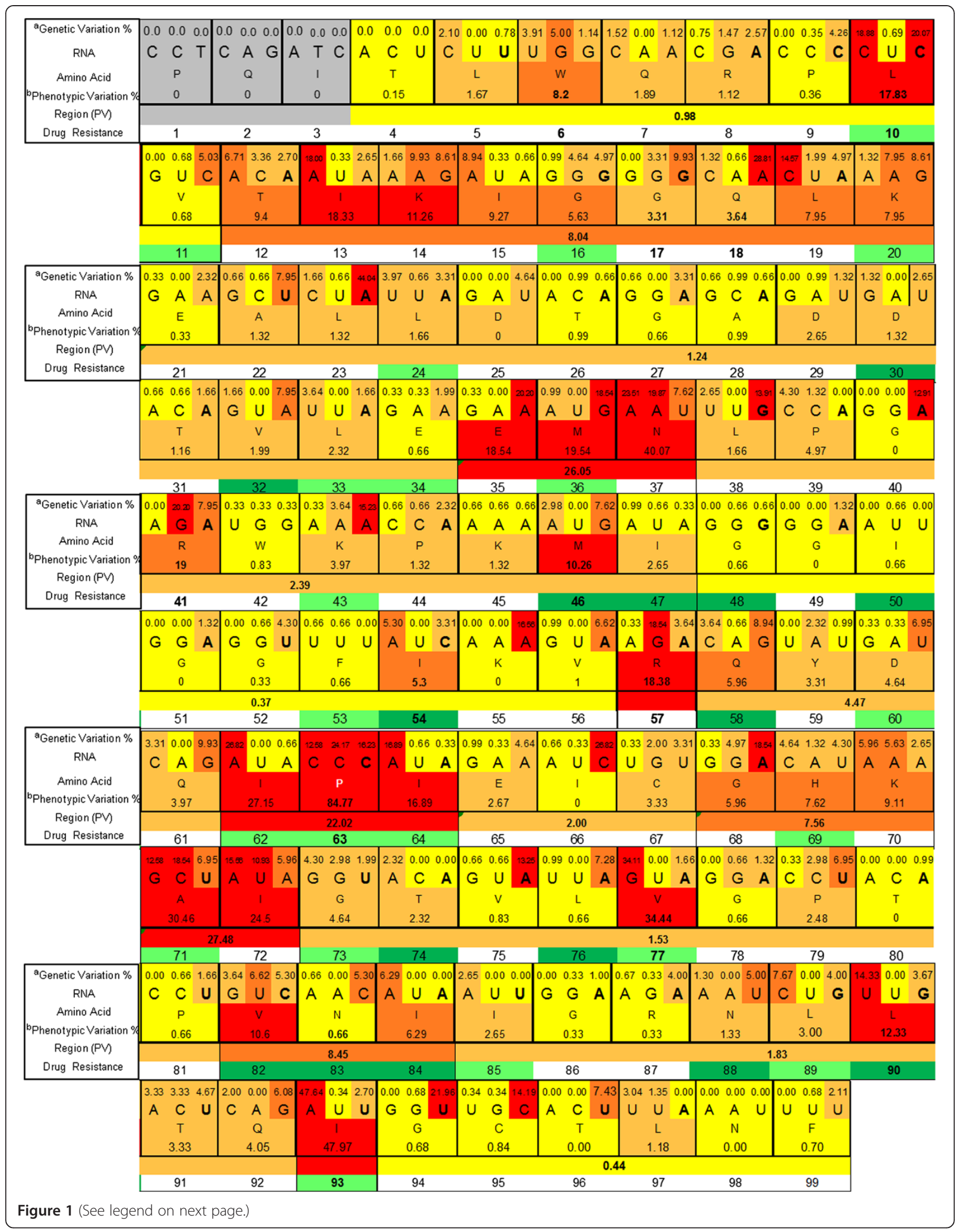


(See figure on previous page.)

Figure 1 Genetic and phenotypic representation of primary structure variation within the HIV-1 protease consensus. Codons $1-3$ are shown in grey and were not included in our analysis. Conserved regions are shown in yellow, semi-conserved regions in ochre, variable regions in orange and highly variable regions in red. The major (dark green) and minor (light green) resistance mutations are indicated for each codon. ${ }^{a}$ Genetic variation = total number of mutations at the nucleotide position/number of sequences evaluated. ${ }^{b}$ Phenotypic variation $=$ total number of mutations at the amino acid position/number of sequences evaluated.

H69 and I84) displayed PV of 5-10\%. Of these, only codons I54 and Q58 were located in conserved and semi-conserved regions, respectively. The remaining 11 codons associated with drug resistance (L10, M36, M46, I62, L63, I64, A71, V77, V82, L90 and I93) had variation $>10 \%$, with L10 and 193 present in conserved regions, and M46, V77 and L90 in semi-conserved regions. There was also a variable PV of $5-10 \%$, in the codons neighbouring the drug resistance positions (T12, I15, L19, G68, and K70), with codons E35, N37, R41, R57, and I72 highly variable. Figure 2 illustrates the mutations with prevalence $\geq 1 \%$ found in the protease region of
HIV-1 that were present in the 151 PR sequences examined. According to the IAS-USA, the mutations associated with drug resistance, with a $p>10 \%$, were L10I, M36I, I62 V, L63P, I64V, A71V/T, V77I, L90M, and $I 93 L[12,36,37]$.

Structural studies of PRs have reported a slight widening of the active site due to mutations associated with drug resistance for the majority of PIs [9,10,38]. However for other inhibitors, such as IDV which is characterized by three aromatic rings, structural changes are caused by mutations at the active site and adjacent positions [39].

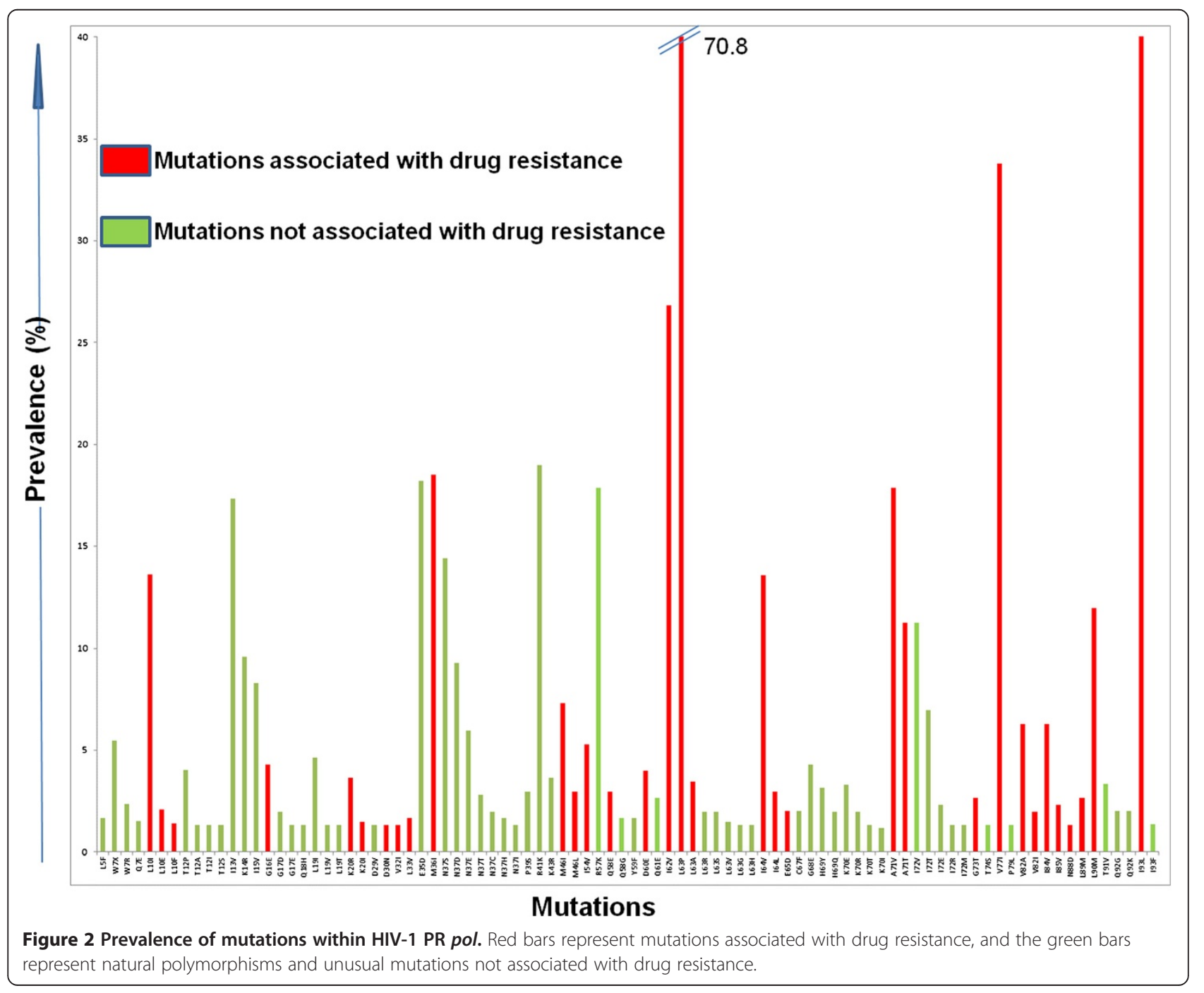


Table 1 Polymorphisms or unusual mutations $(p>1 \%)$ weakly associated with PI resistance in HIV-1 protease from treated and naïve individuals according to the HIVdb

\begin{tabular}{|c|c|c|c|c|c|}
\hline Mutation & $p(\%)$ & $\begin{array}{l}\text { PV } \\
(\%)\end{array}$ & $\begin{array}{l}\text { Region } \\
\text { (PV) }\end{array}$ & Association with drug resistance & Classification \\
\hline W6R & 2.34 & 8.20 & $C(0.98)$ & Found in indinavir-resistant PR [44] & UM \\
\hline T12A/I & $\begin{array}{c}1.34 / \\
1.34\end{array}$ & 9.40 & $V(8.04)$ & $\begin{array}{l}\text { T12A decreased in patients treated with PIs. [45] T12/ appears in cell culture in the presence } \\
\text { of SQV [46] }\end{array}$ & NP/NP \\
\hline $113 \mathrm{~V}$ & 17.33 & 18.33 & $V(8.04)$ & Found in isolates from patients treated with NFV [47] & NP \\
\hline $115 \mathrm{~V}$ & 8.28 & 9.27 & $V(8.04)$ & Associated with reduced virological response to RTV + SQV therapy [48] & NP \\
\hline E350 & 18.21 & 18.54 & $\mathrm{HV}(26.05)$ & Associated with reduced in vivo virological responses to RTV/AMP [49] & NP \\
\hline N37D/E & $\begin{array}{l}9.27 / \\
5.96\end{array}$ & 40.07 & $H V(26.05)$ & N37D appears together with N37E in patient treated with LPV + RTV [50] & NP/NP \\
\hline R41K & 19.00 & 19.00 & SC(2.39) & $\begin{array}{l}\text { Associated with reduced in vivo virological responses to RTV + APV in Pls experienced } \\
\text { patients [49] }\end{array}$ & NP \\
\hline R57K & 17.88 & 18.38 & * & Relatively frequent in patients failing treatment with RTV + SQV [51] & NP \\
\hline L63A & 3.48 & 84.77 & $\mathrm{HV}(22.02)$ & $\begin{array}{l}\text { L63A frequent polymorphism but significantly associated with the antiretroviral treatment } \\
\qquad[39,52]\end{array}$ & NP \\
\hline H69Y & 3.15 & 7.62 & $\vee(7.56)$ & Appears in viruses selected with LPV [53] & NP \\
\hline K70E & 3.31 & 9.11 & $V(7.56)$ & K70E appears in virus selected in cell culture with DRV [54] & NP \\
\hline $172 R$ & 1.32 & 24.50 & $\mathrm{HV}(27.48)$ & Associated with viral rebound during therapy with LPV + RTV [50] & UM \\
\hline
\end{tabular}

p, prevalence; PV, phenotypic variation; C, conserved; SC, semi-conserved; V; variable; HV, highly variable; APV, amprenavir; ATV, atazanavir; DRV, darunavir; IDV, indinavir; RTV, ritonavir; SQV, saquinavir; PIs, protease inhibitors; NP, natural polymorphisms; UM, unusual mutations.

*Values below the 15th percentile or above the 75th percentile were not considered.

\section{Prevalence of natural polymorphisms and unusual} mutations in PRs without established drug resistance

Table 1 shows the natural polymorphisms or unusual mutations with a $p>1 \%$ that were found in the PR sequences of HIV-1 isolated from the Mexican patients. These are weakly associated with PI resistance, but are not included in the IAS-USA guides or the HIVdb as accessory or minor mutations $[16,40,41]$. Of the 14 mutations, only $L 63 A$ and $H 69 Y$ were found in drug resistance positions, and $T 12 \mathrm{~A} / \mathrm{I}, \mathrm{I15} \mathrm{V}, \mathrm{E} 35 \mathrm{D}, \mathrm{N} 37 \mathrm{D} / \mathrm{E}, \mathrm{R} 57 \mathrm{~K}, \mathrm{~K} 70 \mathrm{E}$ and $I 72 \mathrm{~V}$ were contiguous to positions associated with resistance. Overall, these mutations have little effect on drug susceptibility; however, a phenotypic change in any of them could have relevance to the affinity to one or more PIs $[6,42]$. These mutations, in combination with resistance mutations, might have an effect on the dynamics of the evolution of cross-resistance [43].

The I13V (17.33\%), E35D (18.21\%), R41K (19\%) and R57K (17.88\%) mutations had a $p \geq 10 \%$ and were located in polymorphic positions observed in non-B subtypes [35,55,56]. In the HIVdb, W6R and I72R are unusual mutations with a frequency $<0.05 \%$ that only emerge after multiple major and minor resistance mutations [57]. Table 2 shows 41 mutations with a $p>1 \%$ that have not been associated with resistance, 25 are natural polymorphisms and the remaining 16 were unusual mutations. According to phenotypic conservation analysis, the $L 5 F$ and $Q 7 E$ mutations were within the conserved regions, while D29V, P39S, K43R, Q61E, E65D, C67F, P79L, T91V and Q92G/K were within semi-conserved regions. The T12P/S, K14R, G17D/E, Q18H, L19I/V/T,
G68E, H69Q and K70R/T/I mutations were within the variable regions, and N37S/T/C/H/I, L63S/V/R/G/H, I72V/T/E/ $M$ and $I 93 F$ were in highly variable regions.

Among the codons presented in the Table 2, the mutations in positions K43, L63, H69 and I93 were located in sites associated with minor resistance, but the distance between its localization and the enzyme's active site reduces the possibility of the structure contributing to drug resistance. All the described mutations could be due to random transcriptional errors, or positive selection from drug and/ or immunological stressors [37,58]. Generally, natural polymorphisms occur in remote regions away from the active site, and form domains that define the shape of the homodimer. However, unusual mutations are found in positions associated with drug resistance and possibly generate allosteric changes in the binding site that favour enzymatic function, or decrease the affinity with certain PIs [59]. Therefore, the study of such structural changes produced by these emerging mutations may help in determining the new effects of PIs with different affinities.

Figure 3 shows PR tertiary structure positions that are: not associated with PI resistance; weakly associated with PI resistance; associated with PI resistance. We have also presented the locations of natural polymorphisms and unusual mutations (Figure 3). The codons T12, N37, L63, $\mathrm{H} 69, \mathrm{~K} 70$ and I72 include mutations weakly associated with PI resistance $(T 12 A / I, N 37 D / E, L 63 A, H 69 Y, K 70 E$, and $I 72 R)$, and mutations lacking evidence of PI resistance (T12P/S, N37S/T/C/H/I, L63S/V/R/G/H, H69Q, K70R/T/ $I$, and $I 72 \mathrm{~V} / \mathrm{T} / \mathrm{E} / \mathrm{M})$. 
Table 2 Natural polymorphisms and unusual mutations of HIV-1 protease ( $p>1 \%$ ) without evidence of resistance to PIs

\begin{tabular}{|c|c|c|c|c|}
\hline Mutation & $p(\%)$ & PV (\%) & Region (PV) & Classification \\
\hline$L 5 F$ & 1.67 & 1.67 & $C(0.95)$ & UM \\
\hline Q7E & 1.52 & 1.89 & C (0.95) & UM \\
\hline T12P/S & $4.03 / 1.34$ & 9.40 & V (8.04) & NP/NP \\
\hline K14R & 9.60 & 11.26 & V (9.97) & NP \\
\hline G17D/E & $1.99 / 1.32$ & 3.31 & V (9.97) & UM/UM \\
\hline Q18H & 1.32 & 3.64 & V (9.97) & NP \\
\hline L19IN/T & $4.64 / 1.32 / 1.32$ & 7.95 & V (9.97) & NP/NP/NP \\
\hline D29V & 1.32 & 2.65 & SC(1.24) & UM \\
\hline N37S/T/C/H/l & $14.4 / 2.81 / 1.99 / 1.66 / 1.32$ & 40.07 & $H V(26.05)$ & NP/NP/NP/NP/UM \\
\hline P39S & 2.98 & 4.97 & SC(2.09) & NP \\
\hline$K 43 R$ & 3.64 & 3.97 & SC(2.09) & NP \\
\hline Q61E & 2.65 & 3.97 & SC(4.47) & NP \\
\hline L63SN/R/G/H & 1.99/149/1.99/1.32/1.32 & 84.77 & $\mathrm{HV}(22.02)$ & NP/NP/UM/UM/NP \\
\hline E65D & 2.0 & 2.67 & $\mathrm{SC}(2.0)$ & NP \\
\hline C67F & 2.0 & 3.33 & $\mathrm{SC}(2.0)$ & NP \\
\hline G68E & 4.30 & 5.96 & $V(7.56)$ & UM \\
\hline H69Q & 1.99 & 7.62 & $V(7.56)$ & NP \\
\hline KTOR/T/I & $1.99 / 1.32 / 1.16$ & 9.11 & $V(7.56)$ & NP/UM/NP \\
\hline I72V/T/E/M & $11.26 / 6.95 / 2.32 / 1.32$ & 24.50 & $\mathrm{HV}(27.48)$ & NP/NP/NP/UM \\
\hline P79L & 1.32 & 2.48 & SC(1.53) & UM \\
\hline T91V & 3.33 & 3.33 & SC(2.15) & UM \\
\hline Q92G/K & $2.03 / 2.03$ & 4.05 & $\mathrm{SC}(2.15)$ & UM/UM \\
\hline $193 F$ & 1.35 & 47.97 & $H V(47.63)$ & UM \\
\hline
\end{tabular}

p, prevalence; PV, phenotypic variation; C, Conserved; SC, semi-conserved; V, variable; HV, highly variable; NP, natural polymorphisms; UM, unusual mutations.

The $D 29 \mathrm{~V}$ and P79L mutations are located near the active site of the protease, and therefore possibly contribute to the generation of PI resistance. It is of interest to evaluate these unusual mutations in silico, and establish their association with resistance to PIs.

\section{Phenotypic conservation of HIV-1 protease}

Figure 4 shows the conserved, semi-conserved, variable and highly variable regions of PRs according to PV. Mutations were clustered into 15 regions, for amino acids 4-99 of the protease. For average PV calculation, when the asymmetry in the distribution was greater than 1.4 between the 15 th and 75 th percentiles, the residues were not considered. We found three conserved, three variable, three highly variable and six semi-conserved regions for each chain. The positions excluded from the PV calculated for each region were W6, L10, I13, K14, G17, Q18, E35, G40, R41, M46, I54, V56, R57, I63, V77, N83, L90, Q92, I93 and K97. The PV in these codons had very different values from those presented by the codons in their respective regions. According to our model of protease conservation, the LES formed by fragments $23-33$ and 74-78 were in semi-conserved regions
(E21-L34 and G73-P81, except for V77). The LES formed by the 83-92 fragment involved two codons with variable PV, I84 (6.29\%) and L90 (12.33\%), and two codons with semi-conserved PV, T91 (3.33\%) and Q92 (4.05\%) [8,60]. Codon 90 contained a drug resistance mutation (L90M) common for most PIs, with the exception of DRV and TPV, while T91 and Q92 contained the T91V, Q92G, and Q92K mutations, which are classified in the literature as unusual mutations. The prevalence of the L90M, T91V, Q92G, and Q92K mutations was 12.0, 3.33, 2.03 and 2.03\%, respectively. Although the effectiveness and specificity of PR proteolytic activity is determined by its active site (amino acids 25-29), these characteristics are influenced by mutations in neighbouring structures, which mainly affect intramolecular interactions with the active site $[5,38,42,61]$. Contiguous regions and the active site have a semi-conserved state, with a PV of $1.2 \%$. It has been shown that active sites with poor capacity to carry out structural changes help adjust the specificity of natural substrates without losing proteolytic effectiveness [45]. A study that identified the minimal conserved structure of HIV-1 PR, in the presence or absence of drug stress, showed that most of the PV is a product of pharmacological 


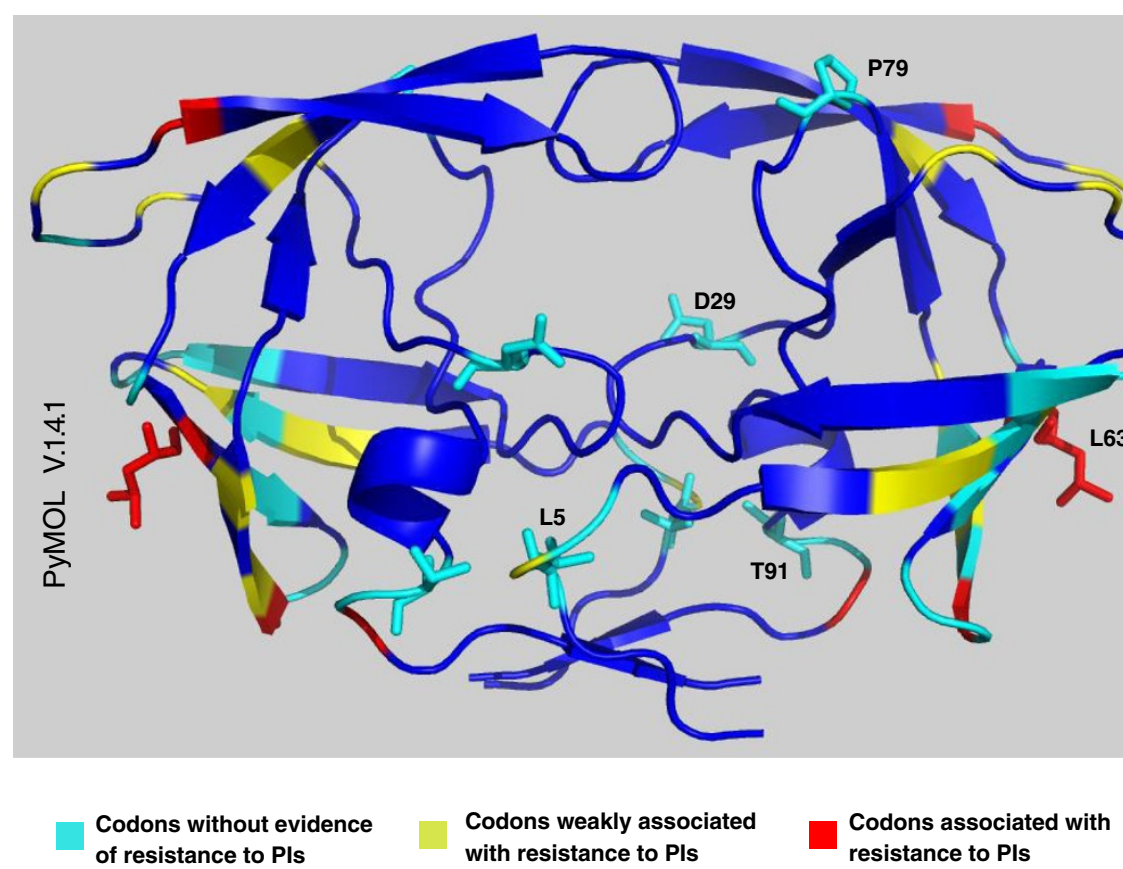

Figure 3 Codons with natural polymorphisms and unusual mutations in the HIV-1 PR tertiary structure. Codons in the PR that were not associated with PI resistance (cyan), weakly associated with PI resistance (yellow), and associated with PI resistance (red).

stress [62]. In contrast, the peripheral structural regions have a relatively high PV (for variable and highly variable regions) courtesy of negative selection, and to a lesser extent through resistance of HIV-1 to immune stress [63,64].

\section{Selective pressure in the pr fragment of HIV-1 pol}

Antiretroviral treatment can exert strong selective pressures within $\mathrm{pol}$, which transcribes $\mathrm{PR}$, reverse transcriptase and integrase [62,65]. We have presented the selection pressure results for 10 codons with natural polymorphisms and unusual mutations (Table 3). According to these results, codons 5, 29, 63, 79, 91 and 93 represent positive pressure $(\mathrm{dN}-\mathrm{dS}>1)$ through the $\mathrm{ML}$ substitution model using the HyPhy algorithm. When these results are compared with the data available in the UCLA HIV Positive Selection Mutation Database, only

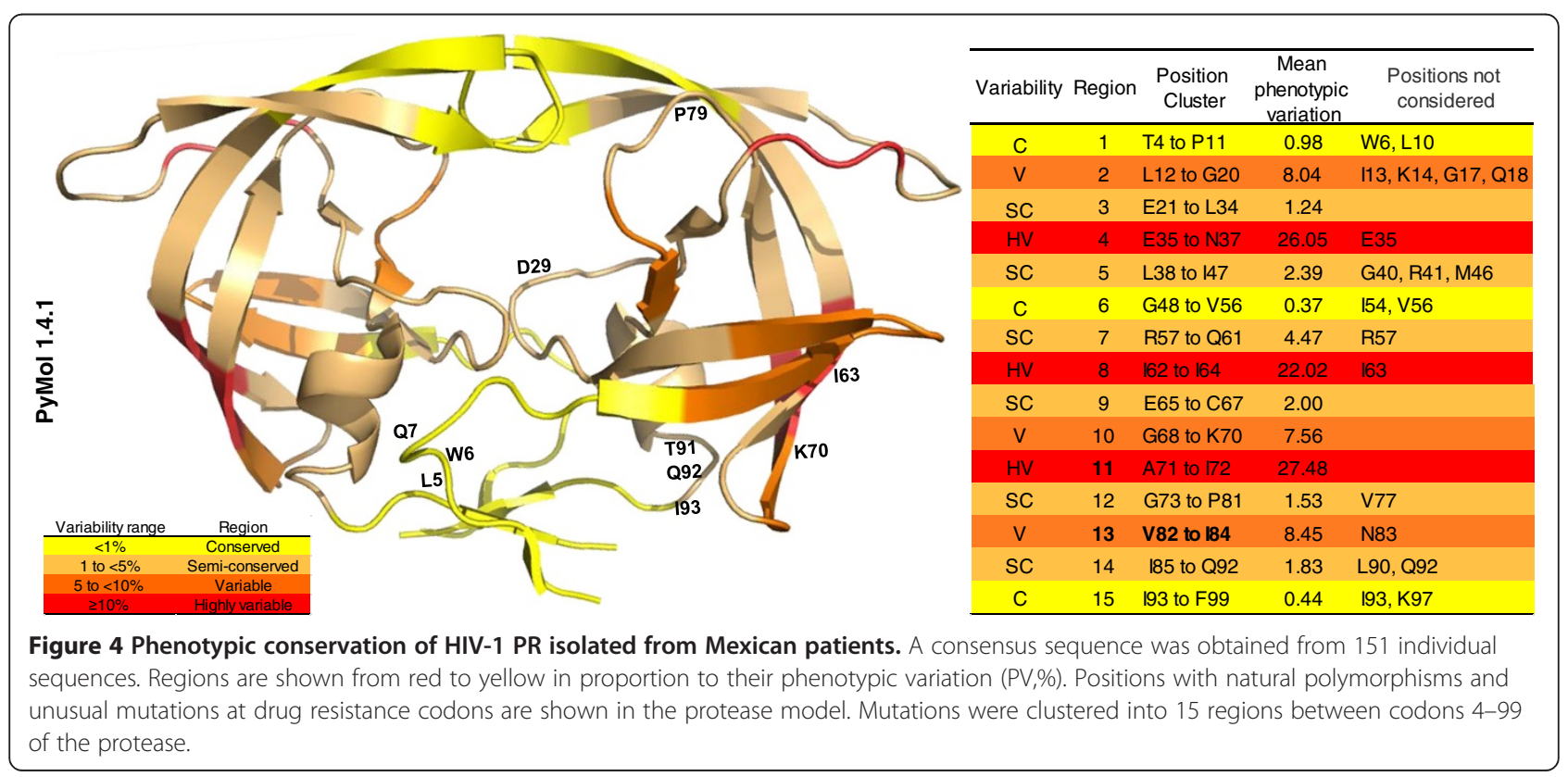


Table 3 Selection pressure for codons with unusual mutations and natural polymorphisms

\begin{tabular}{|c|c|c|c|c|c|c|}
\hline Codon & Triplet & PV (\%) & dN-dS & $\mathrm{dN}-\mathrm{dS}(\mathrm{N})$ & P value* & Mutations \\
\hline 5 & $\mathrm{CTT}$ & 1.67 & 2.29 & 0.48 & 0.285 & L5F \\
\hline 6 & TGG & 8.20 & -5.97 & -1.26 & 0.996 & W6R \\
\hline 7 & CAA & 1.89 & -15.57 & -3.29 & 1.000 & Q7E \\
\hline 29 & GAT & 2.65 & 20.20 & 4.26 & 0.003 & D29V \\
\hline 63 & $\mathrm{CCC}$ & 84.77 & 2.01 & 0.42 & 0.196 & L63A/R/SN/G/H \\
\hline 70 & AAA & 9.11 & -1.51 & -0.32 & 0.964 & K70I \\
\hline 79 & $\mathrm{CCT}$ & 2.48 & 4.44 & 0.94 & 0.190 & P79L \\
\hline 91 & $\mathrm{ACT}$ & 3.33 & 5.01 & 1.12 & 0.086 & T91V \\
\hline 92 & CAG & 4.05 & -15.62 & -3.46 & 0.990 & Q92G;Q92K \\
\hline 93 & ATT & 47.97 & 28.64 & 6.34 & 1.000 & $193 F$ \\
\hline
\end{tabular}

${ }^{*} P<0.05$ was considered statistically significant for positive pressure.

$\mathrm{PV}$, phenotypic variation; $\mathrm{dN}$, number of non-synonymous substitutions per site $(\mathrm{n} / \mathrm{N})$; $\mathrm{dS}$, number of synonymous substitutions per site (s/S); $\mathrm{N}$, normalized; P, probability.

codons 63 and 93 were consistent with positive selection under immunological and/or pharmacological stressors [26]. The difference in selection pressure for codons 5, 29,79 and 91 could be due to variability in the antiretroviral regimen sequences administered to Mexican patients. In addition to positive selection, the aligned sites often evolve at different rates because of other biological factors that include site-specific mutation rates and functional constraints of amino acid substitutions [66].

The codons that were not associated with resistance due to pharmacological stress, and had PV $\geq 2 \%$ were D29 (2.65\%) and P79 (2.48\%). These were located near the active site of the enzyme; T91 (3.33\%) was also found to be necessary for the establishment of the PR dimer. Codons associated with resistance due to pharmacological stress and PV $\geq 2 \%$ were I47 (2.65\%), V82 (10.6\%) and I84 (6.29\%). Only one of these sequences belonged to a naïve individual, with a mutation at V82; the remaining sequences were from treated individuals (three were treated with reverse transcriptase inhibitors only, the remainder were given reverse transcriptase inhibitors and at least one PI).

\section{Structural prediction of mutant HIV-1 PRs}

The molecular structure of all mutant HIV-1 PRs was predicted by comparative homology modelling using the wild-type HIV-1 PR as a template [PDB: 1GNO]. This structure had higher sequence identity compared with the HIV-1 subtype B consensus PR sequence available from the HIVdb. Additional file 1: Table S1 shows the \% identity, the expected value of the alignment with the template sequence (E), and the score for the absolute quality of the models. We modelled the proteins with unusual mutations (L5F, D29V, L63G, L63R, P79L and $T 91 V)$, natural polymorphisms ( $L 63 H$ and $L 63 S)$, and drug-resistant mutant PRs with single mutations or patterns of mutations (D30N, V32I, M36I, M46I, I47V,
G48V, I50V, I5OL, I54M, Q58E, T74P, L76V, V82A, V82L, $N 83 D, N 88 S, I 84 \mathrm{~V}$, and $L 90 M$ ).

The model's accuracy was increased because of the identity between the mutant and template sequences; therefore, we concluded that the model was suitable for all structures. The low $\mathrm{E}$ values obtained from the modelled proteins indicate template identification, and adequate target template alignment [27]. The reliability of the predicted structures with natural polymorphisms and unusual mutations in drug resistance positions ranged $0.87-0.89$, while positions for major mutation proteins ranged 0.83-0.91. The lower QMEAN4 values correlated with mutants containing patterns of resistance, as a result of the reduced identity of these proteins with respect to the template structure [67]. The QMEAN4 values were acceptable for all the modelled structures. Figure 5 shows the overlapping structures of the wild-type PR [PDB: 1GNO] and the $D 29 \mathrm{~V}$ mutant, with high similarity between both structures, as well as a difference in the location of the mutation site (position 29).

D29 plays a crucial role for the folding of retroviral PRs $[38,68]$. Using crystallography, it has been shown that D29 forms hydrogen bonds with R87, which partially constitutes the highly conserved triad, G86 - R87 - D88 [62]. The loss of this specific interaction between $\alpha$ - helix 1 (residues $87-$ 91) and D29 destabilizes the dimer interface [69]. The PR structures of related viruses such as HIV - 2, equine infectious anaemia virus (EIAV), feline immunodeficiency virus (FIV), rous sarcoma virus (RSV) and simian immunodeficiency virus (SIV), also demonstrate a proximity between side chains R87 and D29 [70].

The in silico modelling of mutant proteins generated structures very similar to those obtained by X-ray crystallography. The structures with natural polymorphisms, unusual mutations in drug resistance positions, and drug resistance mutations obtained by comparative homology modelling, were appropriate for molecular docking with their respective inhibitors. 


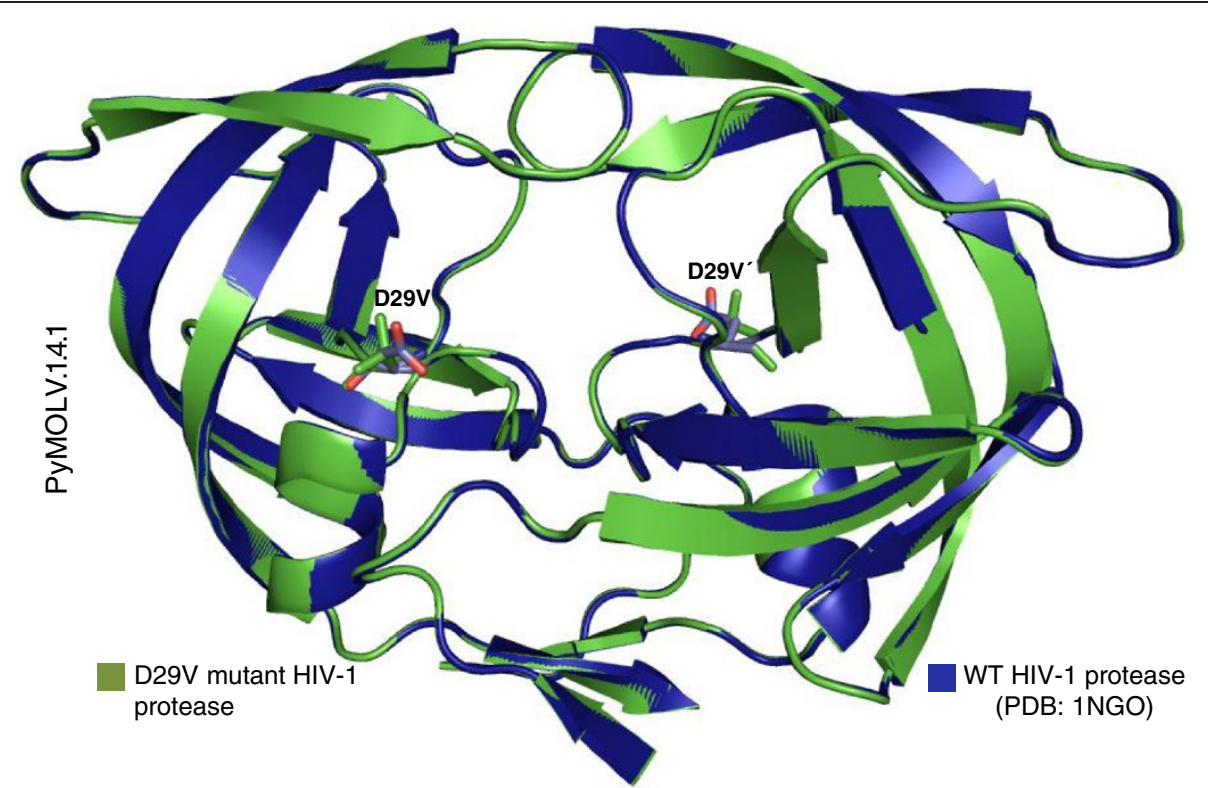

Figure 5 Wild-type and D29V mutant protease structures. The structure of the wild-type HIV-1 protease (WT) was obtained by X-ray crystallography. [PDB: 1GNO] (blue), and the mutant protease (green) can be clearly seen, with the red structures corresponding to the oxygen atoms of D29.

Natural polymorphisms and unusual mutations in PRs and their effects on the free energy of binding by PIs We have presented the free energy of binding $(\mathrm{kcal} / \mathrm{mol})$, as well as the average value of the five lowest energy conformations for the complexes formed by PRs and the main PIs (Table 4). The wild-type PR had the lowest free energy of binding for all PIs, except for IDV, compared with mutant PRs containing major and multiple drug resistance mutations. The magnitudes corresponding to the minor values of the free energy of binding to the reference protein were: wild-type protease-1GNO < major drug-resistant mutant proteases $<$ multiple drug-resistant mutant proteases. The PIs had the greatest degree of affinity for PR 1GNO, consistent with the wild-type PR, whereas reduced affinity for mutant PRs was proportional to the number of mutations [46].

Among the PIs, IDV demonstrated a higher affinity for mutant proteins than PR [PDB: 1GNO]. Additionally, a study that correlated the in vivo genetic resistance of HIV-1 to IDV indicated that the development of resistance occurs through the combined effects of several mutations, which do not confer a measurable degree of resistance when they occur on their own [39]. For the other PIs, significant viral resistance has been shown to be a result of the appearance of one or two substitutions in drug-resistance positions $[40,71]$.

The difference between affinities of complexes formed by wild-type and drug-resistant PRs indicates some contribution of phenotypic changes towards PI resistance $[72,73]$. The complexes with the largest differences involved ATV and DRV, both with a difference of $-1.2 \mathrm{kcal} /$ mol. This indicates high susceptibility of both compounds to drug resistance mutations. Lower differences were observed (between -0.7 and $-0.3 \mathrm{kcal} / \mathrm{mol}$ ) for other complexes, indicating these drug resistance mutations have a minor or supplementary effect [72,73].

We obtained a positive value when we calculated the difference of the free energy of binding between the wildtype-IDV complex and the drug-resistant mutant-IDV complex. This is consistent with a high genetic barrier to resistance for IDV, which has lower susceptibility to drugresistance mutations compared with other PIs [39]. When comparing the free energy of binding between the complexes with drug resistance mutations versus natural polymorphisms and unusual mutation complexes, resistance to ATV, LPV, NFV, and TPV was always observed. The PRs with L5F, D29V, L63G, L63H, L63R, L63S, and P79L mutations had lower or equal free energy of binding to ATV, LPV, NFV and TPV, than those with wild-type or drugresistant PRs.

The complex formed by the $D 29 \mathrm{~V}$ mutant showed considerable differences between the distance of the V29 and D30 $C_{\alpha}$-atoms and the heteroatoms closest to the PIs (Table 4). This is probably because of the absence of the $\mathrm{C}_{\beta}$ carboxyl group in the valine compared with the wildtype D29. The electrostatic interactions exercised by the D29 carboxyl oxygens provide stronger affinity to PIs in the active site, resulting in greater affinity compared with the V29 mutant $[5,74,75]$. The absence of V29 carboxyl oxygens decreases the level of interactions, thus decreasing affinity. Such differences can be observed when measuring the distance between the functional groups of the wild-type, resistant and D29V mutant PRs docked to DRV 
Table 4 Free energy of binding for protease-PI complexes obtained in silico

\begin{tabular}{|c|c|c|c|c|}
\hline Inhibitor & $\begin{array}{l}\text { 1GNO-Ligand } \\
\mathrm{kcal} / \mathrm{mol}\end{array}$ & Mutant protease with major drug resistance mutation $\mathrm{kcal} / \mathrm{mol}$ & $\begin{array}{l}\text { Multiple mutant } \\
\mathrm{kcal} / \mathrm{mol}\end{array}$ & $\begin{array}{l}\text { Mutant protease with emergent mutations } L 5 F / D 29 V / L 63 G / L 63 H / \\
\text { L63R/L63S/P79L/T91V kcal/mol }\end{array}$ \\
\hline Amprenavir & $-8,5(-8,4)$ & $-8,4(-7,9) / / 50 \mathrm{~V}-8,2(-8,12) / / 84 \mathrm{~V}$ & $-8,0(-7,66)$ & $\begin{array}{c}-8,8(-8,38) /-8,7(-8,28) /-8,8(-8,44) /-8,8(-8,3) /-8,8(-8,48) /-8,7(-8,28) /-8,8 \\
(-8,32) /-8,8(-8,48)\end{array}$ \\
\hline Atazanavir & $-8,3(-8,1)$ & $-7,3(-6,94) / / 50 \mathrm{~L}-\mathbf{8}, \mathbf{5}(-\mathbf{8}, \mathbf{1 4}) / / 84 \mathrm{~V}-8,2(-7,98) / \mathrm{N} 88 \mathrm{~S}$ & $-7,1(-6,86)$ & $\begin{array}{c}-7,9(-7,82) /-8,2(-8,14) /-8(-7,62) /-8,1(-7,96) /-8,2(-8,04) /-8,2(-8,06) /-9(-8,8) /- \\
8,2(-8)\end{array}$ \\
\hline Darunavir & $-9,3(-8,96)$ & $-9(-8,54) / / 47 \mathrm{~V}-9,3(-8,86) / 150 \mathrm{~V}-\mathbf{9 , 4} \mathbf{4}(-8,84) / 154 M-9,1(-8,86) / / 84 \mathrm{~V}$ & $-8,1(-7,9)$ & $\begin{array}{c}-9,4(-9) /-8,8(-8,56) /-9,4(-8,9) /-9,4(-8,92) /-9,4(-8,92) /-9,4(-8,88) /-9,4(-8,86) /- \\
9,4(-8,88)\end{array}$ \\
\hline Indinavir & $-10,4(-10,02)$ & $-10,8(-10,5) / M 46 I-10,8(10,4) / V 82 A-10,5(-10,28) / / 84 V$ & $-10,7(-10,26)$ & $\begin{array}{c}-10,4(-10,18) /-10,1(-9,92) /-10,8(-10,48) /-10,4(-10) /-10,4(-10,18) /-10,4(-9,8) /- \\
10,4(-10,02) /-10,7(-10,46)\end{array}$ \\
\hline Lopinavir & $-10,3(-9,84)$ & $-9,9(-9,56) / V 321-9,4(-8,92) / / 47 V-9,5(-8,62) / L 76 V-9,7(-9,24) / V 82 A$ & $-9,7(-9,14)$ & $\begin{array}{c}-9,9(-9,56) /-9,7(-9,18) /-9,6(-9,24) /-9,3(-8,86) /-9(-8,32) /-9,6(-9) /-9,5(-9,2) /-9,6 \\
(-9,42)\end{array}$ \\
\hline Nelfinavir & $-10,3(-9,46)$ & $-10(-9,44) / D 30 N-10,1(-9,8) / L 90 M$ & $-9,9(-9,46)$ & $\begin{array}{c}-10,1(-9,62) /-10,4(-9,8) /-10,1(-9,74) /-10(-9,84) /-10,1(-9,72) /-10,1(-9,74) /-10 \\
(-9,78) /-10,1(-9,7)\end{array}$ \\
\hline Saquinavir & $-10,9(-10,46)$ & $-10,9(-10,6) / G 48 V-10,4(-10,2) / L 90 M$ & $-10,9(-10,54)$ & $\begin{array}{c}-9,9(-9,64) /-10,3(-9,62) /-10,4(-10,06) /-10,6(-10,44) /-10,6(-10,42) /-10,6 \\
(-10,42) /-10,6(-10,5) /-10,5(-10,2)\end{array}$ \\
\hline Tipranavir & $-10,6(-10,1)$ & $\begin{array}{c}-10,4(-9,8) / / 47 V-10,3(-10,04) / Q 58 E-10,2(-10,0) / T 74 P-10,4(-9,9) / V 82 L-10,2 \\
(-9,6) / N 83 D-10,6(-10,12) / / 84 V\end{array}$ & $-9,9(-9,64)$ & $\begin{array}{c}-10,2(-9,62) /-10,1(-9,92) /-10,3(-9,98) /-10,2(-9,88) /-10,2(-9,72) /-10,3(-9,72) /- \\
10,3(-9,72) /-10,2(-9,78)\end{array}$ \\
\hline Ritonavir & $-8,0(-7,85)$ & $\begin{array}{c}-7,82(-7,44) / / 47 \mathrm{~V}-7,8(-7,56) / 150 \mathrm{~V}-7,4(-6,94) / \mathrm{V} 82 \mathrm{~L}-7,87(-7,58) / / 84 \mathrm{~V}-7.9 \\
(-7,72) / L 90 \mathrm{M}\end{array}$ & $-7,26(-6,69)$ & $\begin{array}{c}-8,3(-7,93) /-7,85(-7,54) /-7,75(-7,52) /-7,9(-7,76) /-8,3(-8,14) /-8,2(-8,09) /-8,4 \\
(-8,8) /-7,79(-7,52)\end{array}$ \\
\hline
\end{tabular}

The average value of the five conformations with less free energy of binding of the protease-Pl complex is presented in parentheses. Values that do not correspond to decreasing order of free energy of binding are presented in boldface type. 


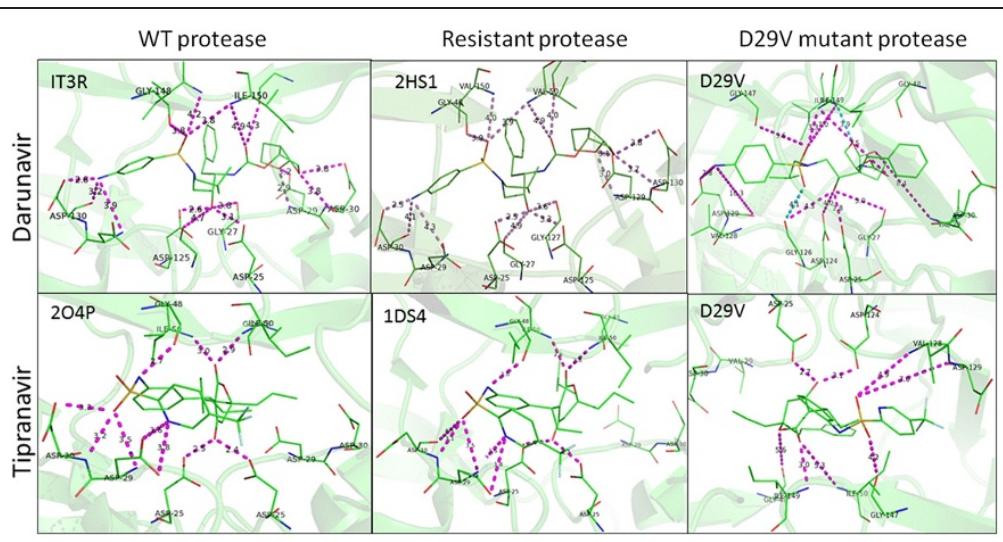

Figure 6 HIV-1 protease structures. Wild-type (WT), resistant and D29V mutant proteases coupled to darunavir (top) and tipranavir (bottom). The numbers in the left upper corner are the PDB ID numbers used to model darunavir and tipranavir with the protease and to measure the distance $(\AA)$ between functional groups (purple).

and TPV (Figure 6). For each natural polymorphism and unusual mutation, Table 5 shows the degree of resistance to PIs based on free energy of binding differences when compared with reference PRs.

Of the emerging mutations, $D 29 \mathrm{~V}$ appears to favour resistance in silico in seven of nine PIs. Designing more effective DRV analogues requires an interaction between D29 and the bis-tetrahydrofuran ring, as this contributes to complex stability [5,42]. All complexes that formed among the PRs with natural polymorphisms, unusual mutations and drug resistance mutations to TPV and LPV had similar free energies of binding. TPV mainly forms hydrogen bonds with residues D25, D29, D30, G48 and I50, while LPV interacts with G27, D29 and D30. A study that elucidated the mechanism by which PIs minimize the harmful effects of resistance mutations, showed that TPV, ATV, LPV, APV, IDV and DRV conserve their antiretroviral activity in the presence of drug resistance mutations. This phenomenon is due to the compensation of the loss of enthalpy $(\Delta \mathrm{H})$ with an entropy gain $(-\mathrm{T} \Delta \mathrm{S})$, except in the case of TPV [75]. Our results are consistent with another report that showed isolated strains with a high level of phenotypic resistance to LPV were susceptible to other PIs [76]. This corresponds with PR resistance to TPV and LPV that contain emerging mutations whose free energies of binding were greater than those obtained with wildtype PR.

We found a high prevalence (89\%) of L63PGHRS mutations in HIV-1 variants isolated from Mexican individuals, probably because of the prevalence of HIV-1 subtype B $[32,33]$. In the present study, among the functional groups found at position 63 (L63G, L63S, L63H and L63R), only glycine had hydrophobic characteristics, while serine was hydrophilic, and histidine and arginine were alkaline. These four mutations conferred resistance to NFV, ATV, TPV and LPV, most probably through an allosteric effect, given that the substitutions were not located close to the residues where the PIs bind [10,74]. Few mutations at position 63 have been examined for their resistance effects to PIs. The L63P mutation has a compensatory effect that increases catalytic activity from $110 \%$ to $530 \%$; when $L 63 P$ is associated with M46I, it forms a combination that is resistant to APV, IDV, LPV or NFV [9,77]. Residue 63 provides hydrophobic contacts between the slit of the loop formed by amino acids 38-42 and a $\beta$-sheet (residues 59-63) [74]. Although the study of mutations in this position has been limited to $L 63 P$ to assess the effect of mutations that provide non-hydrophobic characteristics, alternative mechanisms could be shown by which HIV-1 PR compensates for pharmacological stressors.

\section{Clinical characteristics of patients with unusual mutations} at resistance sites and/or natural polymorphisms

Of the participating individuals, 48 of 151 (31.8\%) showed resistance to at least one PI. Of these, 34 (70.8\%) showed a high level of resistance, four (8.3\%) showed intermediate levels of resistance, and 10 (20.8\%) showed low level resistance.

Of the 151 sequences, 24 (15.9\%) had one or more unusual mutations at resistance sites and/or natural polymorphisms. They were isolated from $21(87.5 \%)$ male and three $(12.5 \%)$ female patients; $70.8 \%$ of whom lived in the central-east of Mexico, and $29.2 \%$ in the north-west. Of these 24 patients, 23 (95.8\%) received antiretroviral therapy, and one $(4.2 \%)$ was naïve to treatment. The nucleoside reverse transcriptase inhibitors (NRTIs) and non-nucleoside reverse transcriptase inhibitors (NNRTIs) used, in order of frequency, were AZT, 3TC, ddI, d4T, ddC, NVP, EFV and ABC. The main PIs used were IDV, RTV and SQV. The average viral load in this group of patients was 228,225 virus copies $/ \mathrm{mL}$ and a mean $\mathrm{CD} 4^{+}$lymphocyte count of 223 cells $/ \mu \mathrm{L}$. According to the case definition of HIV infection and AIDS by the Centers for Disease Control and Prevention (Atlanta, USA) [78], patients were classified as 
Table 5 Distances $(\AA)$ between the amino acid of the protease and the PI heteroatoms

\begin{tabular}{|c|c|c|c|c|c|c|c|}
\hline \multirow[b]{2}{*}{ aa/Chain-PIs } & \multirow[b]{2}{*}{ Wild type } & \multicolumn{2}{|l|}{ Protease } & \multirow{2}{*}{$\begin{array}{l}\text { aa/ } \\
\text { Chain- } \\
\text { Pls }\end{array}$} & \multicolumn{3}{|c|}{ Protease } \\
\hline & & Resistant & Emergent & & Wild type & Resistant & Emergent \\
\hline PR-IDV & [2R5P] & [1K6C] & D29V & PR-LPV & [2Q5K] & [1RV7] & D29V \\
\hline $29 / \mathrm{A}-\mathrm{N}_{2}$ & 6.1 & 6.1 & 5.4 & $25 / \mathrm{A}-\mathrm{O}_{4}$ & 5.4 & 6.8 & 9.1 \\
\hline 29/B-O 4 & 3.9 & 4.2 & 4.8 & $25 / \mathrm{B}^{-\mathrm{O}_{4}}$ & 5.5 & 7.8 & 9.9 \\
\hline $30 / \mathrm{A}-\mathrm{N}_{2}$ & 6.5 & 6.6 & 6.3 & $29 / \mathrm{A}-\mathrm{O}_{1}$ & 5.8 & 10.8 & 6 \\
\hline $30 / \mathrm{B}-\mathrm{O}_{4}$ & 6.3 & 6.4 & 7 & $29 / \mathrm{B}^{-} \mathrm{O}_{3}$ & 6 & 10.3 & 5.3 \\
\hline $82 / \mathrm{A}-\mathrm{O}_{2}$ & 10.1 & 10.7 & 11.2 & $30 / \mathrm{A}-\mathrm{O}_{1}$ & 3.7 & 9.8 & 7.1 \\
\hline $82 / B-N_{1}$ & 6.1 & 6.2 & 7.5 & $30 / \mathrm{B}-\mathrm{O}_{3}$ & 6.7 & 10.1 & 5.3 \\
\hline $84 / \mathrm{A}-\mathrm{O}_{2}$ & 8.3 & 8.2 & 9.3 & $84 / \mathrm{A}-\mathrm{O}_{4}$ & 8.2 & 10.1 & 10.4 \\
\hline $84 / B-N_{1}$ & 7.9 & 7.9 & 8.4 & $84 / \mathrm{B}-\mathrm{O}_{3}$ & 7.6 & 8.1 & 8.2 \\
\hline PR-SQV & [30XC] & {$[3 \mathrm{CYW}]$} & D29V & PR-RTV & [3NDX] & [1RL8] & D29V \\
\hline $29 / A-O_{D 1}$ & 4.1 & 5.3 & 3.5 & $29 / \mathrm{A}-\mathrm{O}_{76}$ & 4 & 3.8 & 4.9 \\
\hline $29 / \mathrm{B}-\mathrm{N}_{3}$ & 6.1 & 6 & 7.5 & $29 / \mathrm{B}-\mathrm{N}_{5}$ & 5.6 & 4 & 5.1 \\
\hline $30 / A-O_{D 1}$ & 3.8 & 4.2 & 3.8 & $30 / \mathrm{A}-\mathrm{O}_{76}$ & 6.1 & 6.1 & 6.9 \\
\hline $30 / \mathrm{B}-\mathrm{N}_{3}$ & 6.5 & 6.4 & 7.5 & $30 / \mathrm{B}-\mathrm{S}_{3}$ & 4 & 5.5 & 8.8 \\
\hline $48 / A-N_{D 2}$ & 3.4 & 5.6 & 7.9 & $82 / A-N_{11}$ & 9.4 & 9.5 & 9.6 \\
\hline $48 / \mathrm{B}-\mathrm{N}_{3}$ & 4 & 6.3 & 6.3 & $82 / \mathrm{B}^{-} \mathrm{O}_{7}$ & 10.5 & 10.3 & 11.6 \\
\hline PR-APV & [3NU3] & [3NU4] & D29V & PR-DRV & [IT3R] & [2HS1] & D29V \\
\hline $29 / \mathrm{A}-\mathrm{O}_{6}$ & 4.5 & 4.2 & 4 & $29 / \mathrm{A}-\mathrm{O}_{26}$ & 3.9 & 4.1 & 10.4 \\
\hline $29 / B-N_{3}$ & 4.3 & 4.6 & 7.6 & 29/B-N 1 & 4.6 & 4.4 & 7.3 \\
\hline $30 / \mathrm{A}-\mathrm{O}_{6}$ & 4.5 & 3.8 & 3.8 & $30 / \mathrm{A}-\mathrm{O}_{26}$ & 3.8 & 3.8 & 12.3 \\
\hline $30 / \mathrm{B}-\mathrm{N}_{3}$ & 3.3 & 3.7 & 10.7 & $30 / \mathrm{B}-\mathrm{N}_{1}$ & 3.8 & 3.7 & 9.5 \\
\hline $32 / \mathrm{A}-\mathrm{O}_{6}$ & 6.6 & 6.6 & 6.9 & $32 / \mathrm{A}-\mathrm{O}_{26}$ & 7.2 & 7.5 & 13.9 \\
\hline $32 / B-N_{3}$ & 6.3 & 6.3 & 15 & $32 / B-N_{1}$ & 6.1 & 7.6 & 13.3 \\
\hline PR-TPV & [204P] & [1DS4] & D29V & PR-ATV & [3EKY] & [30XX] & D29V \\
\hline $29 / A-N_{28}$ & 6.1 & 6.2 & 9.6 & $29 / \mathrm{A}-\mathrm{O}_{\mathrm{Al}}$ & 3.9 & 5.1 & 5.6 \\
\hline 29/B-O, & 9.1 & 9.4 & 8.4 & $29 / B-O_{A J}$ & 3.9 & 4 & 8.3 \\
\hline $30 / \mathrm{A}-\mathrm{N}_{28}$ & 6.2 & 6 & 8.7 & $30 / \mathrm{A}-\mathrm{O}_{\mathrm{Al}}$ & 6.1 & 6 & 8.7 \\
\hline 30/B- ${ }_{1}$ & 10 & 10.2 & 8.6 & $30 / \mathrm{B}-\mathrm{O}_{\mathrm{A}}$ & 6 & 6 & 8.5 \\
\hline $82 / \mathrm{A}-\mathrm{O}_{8}$ & 10.7 & 10 & 10.2 & $50 / \mathrm{A}-\mathrm{O}_{1}$ & 5.7 & 5.6 & 4.8 \\
\hline $82 / \mathrm{B}-\mathrm{O}_{7}$ & 10.3 & 9.9 & 7.7 & $50 / \mathrm{B}-\mathrm{O}_{1}$ & 5.3 & 5.4 & 3.6 \\
\hline
\end{tabular}


Table 5 Distances (Å) between the amino acid of the protease and the PI heteroatoms (Continued)

\begin{tabular}{lccc}
\hline $84 / \mathrm{A}-\mathrm{O}_{8}$ & 8.3 & 8.1 & 8.5 \\
$84 / \mathrm{B}-\mathrm{O}_{8}$ & 8.4 & 7.8 & 8.1 \\
$\mathrm{PR}-\mathrm{NFV}$ & {$[3 \mathrm{EKX}]$} & {$[2 \mathrm{PYM}]$} & $\mathrm{D} 29 \mathrm{~V}$ \\
$29 / \mathrm{A}-\mathrm{N}_{12}$ & 5.9 & 6.3 & 5.8 \\
$29 / \mathrm{B}-\mathrm{O}_{38}$ & 5 & 4.4 & 3.8 \\
$30 / \mathrm{A}-\mathrm{N}_{12}$ & 6.4 & 6.7 & 6.3 \\
$30 / \mathrm{B}-\mathrm{O}_{38}$ & 3.9 & 3.7 & 3.7
\end{tabular}

The classification of atoms corresponds to the PDB file visualized in PyMOL. Measurements correspond to the distance between the alpha carbon of the PR amino acids and the heteroatoms of the inhibitor, and are expressed as number of amino acids/chain PR - PI heteroatom.

PIs, protease inhibitors; aa, amino acid; PR, protease; APV, amprenavir; ATV, atazanavir; DRV, darunavir; IDV, indinavir; LPV, lopinavir; RTV, ritonavir; SQV, saquinavir; TPV, tipranavir. 
asymptomatic $(n=2,8.5 \%)$, symptomatic $(n=6,25 \%)$, AIDS $(n=12,50 \%)$, and of unknown clinical category $(n=$ $4,16.5 \%)$.

\section{Conclusions}

The use of bioinformatics to identify potential mutations that confer resistance to antiretroviral drugs allows researchers to develop realistic three-dimensional models that illustrate the atomic interactions between an enzyme and its substrate. In silico, the structural correlation of natural polymorphisms and unusual mutations of drug resistance codons, allows the identification of HIV-1 variants resistant to PIs. The D29V mutation increases the probability of resistance to PIs as it generates unstable complexes at the HIV-1 protease active site. The prevalence of this mutation in different populations should be further studied, and parallel crystallographic studies are required to confirm our in silico findings.

Among mutant PRs-PIs complexes evaluated, TPV and LPV had free energies of binding greater than those obtained with wild-type PRs.

Furthermore, the presence of a high rate of $L 63 P, 193 L$, $V 77 I$ and $I 62 \mathrm{~V}$ polymorphisms among the Mexican population is similar to that observed in patients that underwent antiretroviral treatments in other American and western European countries. These data reinforced the knowledge regarding the molecular epidemiology of the HIV-1 subtype $B$ in Mexico through the presence of HIV polymorphisms.

\section{Endnote}

The Contents of this publication are the authors responsibility and do not necessarily represent the official views of the Instituto Mexicano del Seguro Social.

\section{Additional file}

Additional file 1: Table S1. Identity value, expected value and QMEAN analyses of mutant proteases models tested to estimate the quality of the predicted structure.

\footnotetext{
Abbreviations

FDA: USA Food and Drug Administration; HAART: Highly Active Antiretroviral Therapy; HIV: Human Immunodeficiency Virus; LES: Local Elementary Structures; MEGA: Molecular Evolution Genetics Analysis; PDB: Protein Date Bank; PIs: Protease Inhibitors; PV: Phenotypic Variation; QMEAN: Qualitative Model Energy Analysis; PR: protease; LANL: Los Alamos HIV sequence Database; HIVDB: HIV Drug Resistance Database; p: prevalence; M: Mutation; ML: Maximun Likelihood; dS: synonimous site divergence; $\mathrm{dN}$ : nonsynonimous site divergence.
}

\section{Competing interests}

The authors declare that they have no competing interest.

\section{Authors' contributions}

CMM, MED, MVT and MFS performed sequences and bioinformatics analyses. EW designed the study. AVO, FGG, MCM and LGFR provided clinical samples and collected the data. BTM performed the data analysis, CMM and EW wrote the manuscript. All authors read and approved the final manuscript.

\section{Acknowledgements}

The study was funded in part by the Instituto Mexicano del Seguro Social, Grant Number FIS/IMSS/G09/752. The authors wish to thank Ms. Luz SegoviaSantos for her editorial services and to Greg Davies for his English revision services

\section{Author details}

1Doctorado en Farmacología, Departamento de Fisiología, Centro Universitario de Ciencias de la Salud, Universidad de Guadalajara, Guadalajara 44340, México. ${ }^{2}$ Laboratorio de Inmunodeficiencias y Retrovirus Humanos, Centro de Investigación Biomédica de Occidente, CMNO, IMSS, Guadalajara 44340, México. ${ }^{3}$ Unidad de Investigación Cardiovascular, Departamento de Fisiología, Centro Universitario de Ciencias de la Salud, Universidad de Guadalajara, Guadalajara 44340, México. ${ }^{4}$ División de Excelencia Clínica, Coordinación Médica de Unidades de Alta Especialidad, Unidad de Atención Médica, IMSS, México, D.F 06700, México. ${ }^{5}$ UMAE, Hospital de Especialidades, CMNO, IMSS, Guadalajara 44340, México. ${ }^{6}$ Departamento de Producción Agrícola, Centro Universitario de Ciencias Biológicas y Agropecuarias, Universidad de Guadalajara, Zapopan 45110, México. ${ }^{7}$ Departamento de Clínicas Médicas, Centro Universitario de Ciencias de la Salud, Universidad de Guadalajara, Guadalajara 44340, México. ${ }^{8}$ Departamento de Farmacobiología, CUCEI, Universidad de Guadalajara, Guadalajara 44430, México.

Received: 27 June 2012 Accepted: 5 March 2014

Published: 15 March 2014

\section{References}

1. Shafer RW, Kantor R, Gonzales MJ: The genetic basis of HIV-1 resistance to reverse transcriptase and protease inhibitors. AIDS Rev 2000, 2:211-228.

2. Rambaut A, Posada D, Crandall KA, Holmes EC: The causes and consequences of HIV evolution. Nat Rev Genet 2004, 5:52-61.

3. Ribeiro RM, Bonhoeffer S: Production of resistant HIV mutants during antiretroviral therapy. Proc Natl Acad Sci USA 2000, 97:7681-7686.

4. Adamson CS, Freed EO: Recent progress in antiretrovirals - lessons from resistance. Drug Discov Today 2008, 13:424-432.

5. Ghosh AK, Sridhar PR, Leshchenko S, Hussain AK, Li J, Kovalevsky AY, Walters DE, Wedekind JE, Grum-Tokars V, Das D, Koh Y, Maeda K, Gatanaga H, Weber IT, Mitsuya H: Structure-based design of novel HIV-1 protease inhibitors to combat drug resistance. J Med Chem 2006, 49:5252-5261.

6. Ohtaka H, Schon A, Freire E: Multidrug resistance to HIV-1 protease inhibition requires cooperative coupling between distal mutations. Biochemistry 2003, 42:13659-13666.

7. Broglia RA, Provasi D, Vasile F, Ottolina G, Longhi R, Tiana G: A folding inhibitor of the HIV-1 protease. Proteins 2006, 62:928-933.

8. Broglia RA, Tiana G, Sutto L, Provasi D, Simona F: Design of HIV-1-PR inhibitors that do not create resistance: blocking the folding of single monomers. Protein Sci 2005, 14:2668-2681.

9. Piana $\mathrm{S}$, Carloni P, Rothlisberger U: Drug resistance in HIV-1 protease: Flexibility-assisted mechanism of compensatory mutations. Protein Sci 2002, 11:2393-2402.

10. Hornak V, Simmerling C: Targeting structural flexibility in HIV-1 protease inhibitor binding. Drug Discov Today 2007, 12:132-138.

11. Shafer RW, Rhee SY, Pillay D, Miller V, Sandstrom P, Schapiro JM, Kuritzkes DR, Bennett D: HIV-1 protease and reverse transcriptase mutations for drug resistance surveillance. AIDS 2007, 21:215-223.

12. Johnson VA, Calvez V, Günthard HF, Paredes R, Pillay D, Shafer R, Wensing AM, Richman DD: Update of the drug resistance mutations in HIV-1: March 2013. Top Antivir Med 2013, 21:4-12.

13. Johnson JA, Li JF, Wei X, Lipscomb J, Irlbeck D, Craig C, Smith A, Bennett DE, Monsour M, Sandstrom P, Lanier ER, Heneine W: Minority HIV-1 drug resistance mutations are present in antiretroviral treatment-naive populations and associate with reduced treatment efficacy. PLoS Med 2008, 5:e158.

14. Benson DA, Karsch-Mizrachi I, Lipman DJ, Ostell J, Rapp BA, Wheeler DL: GenBank. Nucleic Acids Res 2002, 30:17-20.

15. Rose PP, Korber BT: Detecting hypermutations in viral sequences with an emphasis on G - > A hypermutation. Bioinformatics 2000, 16:400-401.

16. Rhee SY, Gonzales MJ, Kantor R, Betts BJ, Ravela J, Shafer RW: Human immunodeficiency virus reverse transcriptase and protease sequence database. Nucleic Acids Res 2003, 31:298-303. 
17. Rozanov M, Plikat U, Chappey C, Kochergin A, Tatusova T: A web-based genotyping resource for viral sequences. Nucleic Acids Res 2004, 32:W654-W659.

18. Tamura K, Peterson D, Peterson N, Stecher G, Nei M, Kumar S: MEGA5: Molecular evolutionary genetics analysis using maximum likelihood, evolutionary distance, and maximum parsimony methods. Mol Biol Evol 2011, 28:2731-2739.

19. Kuiken C, Korber B, Shafer RW: HIV sequence databases. AIDS Rev 2003, 5:52-61.

20. Larkin MA, Blackshields G, Brown NP, Chenna R, McGettigan PA, McWilliam H, Valentin F, Wallace IM, Wilm A, Lopez R: Clustal W and Clustal X version 2.0. Bioinformatics 2007, 23:2947-2948.

21. Kimura M: A simple method for estimating evolutionary rates of base substitutions through comparative studies of nucleotide sequences. J Mol Evol 1980, 16:111-120.

22. Rhee SY, Kantor R, Katzenstein DA, Camacho R, Morris L, Sirivichayakul S, Jorgensen L, Brigido LF, Schapiro JM, Shafer RW, for the International Non Subtype: HIV-1 pol mutation frequency by subtype and treatment experience: extension of the HIVseq program to seven non-B subtypes. AIDS 2006, 20:643-651.

23. Pond SL, Frost SD, Muse SV: HyPhy: hypothesis testing using phylogenies. Bioinformatics 2005, 21:676-679.

24. Yang Z, Goldman N, Friday A: Comparison of models for nucleotide substitution used in maximum-likelihood phylogenetic estimation. Mol Biol Evol 1994, 11:316-324.

25. Muse SV, Gaut BS: A likelihood approach for comparing synonymous and nonsynonymous nucleotide substitution rates, with application to the chloroplast genome. Mol Biol Evol 1994, 11:715-724.

26. Pan C, Kim J, Chen L, Wang Q, Lee C: The HIV positive selection mutation database. Nucleic Acids Res 2007, 35:D371-D375.

27. Bordoli L, Kiefer F, Arnold K, Benkert P, Battey J, Schwede T: Protein structure homology modeling using SWISS-MODEL workspace. Nat Protocols 2008, 4:1-13.

28. Berman HM, Westbrook J, Feng Z, Gilliland G, Bhat TN, Weissig H, Shindyalov IN, Bourne PE: The protein data bank. Nucleic Acids Res 2000, 28:235-242.

29. Benkert P, Tosatto SCE, Schomburg D: QMEAN: a comprehensive scoring function for model quality assessment. Proteins 2008, 71:261-277.

30. Trott O, Olson AJ: AutoDock Vina: improving the speed and accuracy of docking with a new scoring function, efficient optimization, and multithreading. J Comput Chem 2010, 31:455-461.

31. Delano WL: The PyMOL Molecular Graphics System. 2002 [http://www.pymol org]

32. Vazquez-Valls E, Escoto-Delgadillo M, Lopez-Marquez FC, Castillero-Manzano M, Echegaray-Guerrero E, Bitzer-Quintero OK, Kobayashi-Gutierrez A, TorresMendoza BM: Molecular epidemiology of HIV type 1 in Mexico: emergence of BG and BF intersubtype recombinants. AIDS Res Hum Retroviruses 2010, 26:777-781.

33. Avila-Ríos S, García-Morales C, Garrido-Rodríguez D, Ormsby CE, HernándezJuan R, Andrade-Villanueva J, González-Hernández LA, Torres-Escobar I, Navarro-Álvarez S, Reyes-Terán G, Mexican HIV Molecular Epidemiology Project Group: National prevalence and trends of HIV transmitted drug resistance in Mexico. PLoS One 2011, 6:e27812.

34. Hartman $J L$, Garvik B, Hartwell L: Principles for the buffering of genetic variation. Science 2001, 9(291):1001-4.

35. Bürger $R$, Willensdorfer M, Nowak MA: Why are phenotypic mutation rates much higher than genotypic mutation rates? Genetics 2006, 172:197-206.

36. Rhee SY, Liu TF, Holmes SP, Shafer RW: HIV-1 subtype b protease and reverse transcriptase amino acid covariation. PLOS Comput Biol 2007 3:e87

37. Chen L, Lee C: Distinguishing HIV-1 drug resistance, accessory, and viral fitness mutations using conditional selection pressure analysis of treated versus untreated patient samples. Biol Direct 2006, 1:14.

38. Bonomi M, Gervasio FL, Tiana G, Provasi D, Broglia RA, Parrinello M: Insight into the folding inhibition of the HIV-1 protease by a small peptide. Biophys J 2007, 93:2813-2821.

39. Condra JH, Holder DJ, Schleif WA, Blahy OM, Danovich RM, Gabryelski LJ, Graham DJ, Laird D, Quintero JC, Rhodes A, Robbins HL, Roth E, Shivaprakash M, Yang T, Chodakewitz JA, Deutsch PJ, Leavitt RY, Massari FE, Mellors JW, Squires KE, Steigbigel RT, Teppler H, Emini EA: Genetic correlates of in vivo viral resistance to indinavir, a human immunodeficiency virus type 1 protease inhibitor. J Virol 1996, 70:8270-8276

40. Zhang J, Hou T, Wang W, Liu JS: Detecting and understanding combinatorial mutation patterns responsible for HIV drug resistance. Proc Natl Acad Sci USA 2010, 107:1321-1326

41. Shafer RW, Rhee SY, Bennett DE: Consensus drug resistance mutations for epidemiological surveillance: basic principles and potential controversies. Antivir Ther 2008, 13(Suppl 2):59-68.

42. Ghosh AK, Chapsal BD, Weber IT, Mitsuya H: Design of HIV protease inhibitors targeting protein backbone: an effective strategy for combating drug resistance. Acc Chem Res 2007, 41:78-86.

43. Haq O, Levy R, Morozov A, Andrec M: Pairwise and higher-order correlations among drug-resistance mutations in HIV-1 subtype $B$ protease. BMC Bioinformatics 2009, 10:S10.

44. Melnick L, Yang SS, Rossi R, Zepp C, Heefner D: An Escherichia coli expression assay and screen for human immunodeficiency virus protease variants with decreased susceptibility to indinavir. Antimicrob Agents Chemother 1998, 42:3256-65.

45. Svicher V, Ceccherini-Silberstein F, Erba F, Santoro M, Gori C, Bellocchi MC, Giannella S, Trotta MP, Monforte A, Antinori A, Perno CF: Novel human immunodeficiency virus type 1 protease mutations potentially involved in resistance to protease inhibitors. Antimicrob Agents Chemother 2005, 49:2015-2025.

46. Jacobsen H, Yasargil K, Winslow DL, Craig JC, Krohn A, Duncan IB, Mous J: Characterization of human immunodeficiency virus type 1 mutants with decreased sensitivity to proteinase inhibitor Ro 31-8959. Virology 1995, 206:527-534.

47. Markowitz M, Conant M, Hurley A, Schluger R, Duran M, Peterkin J, Chapman S, Patick A, Hendricks A, Yuen GJ, Hoskins W, Clendeninn N, Ho DD: A preliminary evaluation of nelfinavir mesylate, an inhibitor of human immunodeficiency virus (HIV)-1 protease, to treat HIV infection. $J$ Infect Dis 1998, 177:1533-40.

48. Marcelin AG, Flandre P, De Mendoza C, Roquebert B, Peytavin G, Valer L, Wirden M, Abbas S, Katlama C, Soriano V, Calvez V: Clinical validation of saquinavir/ritonavir genotypic resistance score in protease-inhibitorexperienced patients. Antivir Ther 2007, 12:247-52.

49. Marcelin AG, Lamotte C, Delaugerre C, Ktorza N, Ait Mohand H, Cacace R, Bonmarchand M, Wirden M, Simon A, Bossi P, Bricaire F, Costagliola D, Katlama C, Peytavin G, Calvez V, Genophar Study Group: Genotypic inhibitory quotient as predictor of virological response to ritonaviramprenavir in human immunodeficiency virus type 1 protease inhibitorexperienced patients. Antimicrob Agents Chemother 2003, 47:594-600.

50. Molla A, Brun S, Mo H, Real K, Podding J, Bernstein B, Hertogs K, Larder B, Lie $Y$, Hellmann N, Vasavanonda S, Chernyavskiy T, Freimuth W, Japour A, Sun E, Kempf D: Genotypic and phenotypic analysis of viral isolates from subjects with detectable viral load on therapy with ABT-378/ritonavir. Antiviral Ther 2000, 5(Suppl 3):30.

51. Harrigan PR, Hertogs K, Verbiest W, Pauwels R, Larder B, Kemp S, Bloor S, Yip $B$, Hogg R, Alexander C, Montaner JS: Baseline HIV drug resistance profile predicts response to ritonavir-saquinavir protease inhibitor therapy in a community setting. AIDS 1999, 13:1863-1871.

52. Shafer RW, Hsu P, Patick AK, Craig C, Brendel V: Identification of biased amino acid substitution patterns in human immunodeficiency virus type 1 isolates from patients treated with protease inhibitors. J Virol 1999, 73:6197-6202

53. Carrillo A, Stewart KD, Sham HL, Norbeck DW, Kohlbrenner WE, Leonard JM, Kempf DJ, Molla A: In vitro selection and characterization of human immunodeficiency virus type 1 variants with increased resistance to ABT-378, a novel protease inhibitor. J Virol 1998, 72:7532-7541.

54. De Meyer S, Azijn H, Van Ginderen M, De Baere I, Pauwels R, De Béthune MP: In vitro selection experiments demonstrate an increased genetic barrier to resistance development to TMC114 as compared with currently licensed protease inhibitors. Antiviral Ther 2002, 7:S5.

55. Coman RM, Robbins AH, Fernandez MA, Gilliland $C T$, Sochet AA, Goodenow MM, McKenna R, Dunn BM: The contribution of naturally occurring polymorphisms in altering the biochemical and structural characteristics of HIV-1 subtype C protease. Biochemistry 2008, 47:731-743.

56. Kantor R, Katzenstein DA, Efron B, Carvalho AP, Wynhoven B, Cane P, Clarke J, Sirivichayakul S, Soares MA, Snoeck J, Pillay C, Rudich H, Rodrigues R, Holguin A, Ariyoshi K, Bouzas MB, Cahn P, Sugiura W, Soriano V, Brigido LF, Grossman Z, Morris L, Vandamme AM, Tanuri A, Phanuphak P, Weber JN, 
Pillay D, Harrigan PR, Camacho R, Schapiro JM, et al. Impact of HIV-1 subtype and antiretroviral therapy on protease and reverse transcriptase genotype: results of a global collaboration. PLoS Med 2005, 2:e112.

57. The HIVdb Release Notes - HIV Drug Resistance Database. [http://hivdb. stanford.edu/DR/asi/releaseNotes/index.html]

58. Ali A, Bandaranayake RM, Cai Y, King NM, Kolli M, Mittal S, Murzycki JF, Nalam MN, Nalivaika EA, Ozen A, Prabu-Jeyabalan MM, Thayer K, Schiffer CA: Molecular basis for drug resistance in HIV-1 protease. Viruses 2010, 2:2509-2535.

59. Kozisek M, Bray J, Rezacova P, Saskova K, Brynda J, Pokorna J, Mammano F, Rulisek L, Konvalinka J: Molecular analysis of the HIV-1 resistance development: enzymatic activities, crystal structures, and thermodynamics of nelfinavir-resistant HIV protease mutants. J Mol Biol 2007, 374:1005-1016.

60. Broglia RA: Learning to design resistance proof drugs from folding. Eur Phys J D At Mol Opt Plasma Phys 2009, 51:137-151.

61. Parera M, Fernández G, Clotet B, Martinez MA: HIV-1 protease catalytic efficiency effects caused by random single amino acid substitutions. Mol Biol Evol 2007, 24:382-387.

62. Ceccherini-Silberstein F, Erba F, Gago F, Bertoli A, Forbici F, Bellocchi MC, Gori C, D'Arrigo R, Marcon L, Balotta C, Antinori A, Monforte A, Perno CF: Identification of the minimal conserved structure of HIV-1 protease in the presence and absence of drug pressure. AIDS 2004, 18:F11-F19.

63. Boeri E, Gianotti N, Canducci F, Hasson H, Giudici B, Castagna A, Lazzarin A Clementi M: Evolutionary characteristics of HIV type 1 variants resistant to protease inhibitors in the absence of drug-selective pressure. AIDS Res Hum Retroviruses 2003, 19:1151-1153.

64. Karlsson AC, Deeks SG, Barbour JD, Heiken BD, Younger SR, Hoh R, Lane M, Sällberg M, Ortiz GM, Demarest JF, Liegler T, Grant RM, Martin JN, Nixon D: Dual pressure from antiretroviral therapy and cell-mediated immune response on the human immunodeficiency virus type 1 protease gene. J Virol 2003, 77:6743-6752.

65. Prabu-Jeyabalan M, Nalivaika EA, King NM, Schiffer CA: Viability of a drugresistant human immunodeficiency virus type 1 protease variant: structural insights for better antiviral therapy. J Virol 2003, 77:1306-1315.

66. De Oliveira T, Salemi M, Gordon M, Vandamme AM, Van Rensburg EJ, Engelbrecht S, Coovadia HM, Cassol S: Mapping sites of positive selection and amino acid diversification in the HIV genome. Genetics 2004, 167:1047-1058.

67. Arnold K, Bordoli L, Kopp J+, Schwede T: The SWISS-MODEL workspace: a web-based environment for protein structure homology modelling. Bioinformatics 2006, 22:195-201.

68. Bonomi M, Barducci A, Gervasio FL, Parrinello M: Multiple routes and milestones in the folding of HIV-1 protease monomer. PLOS ONE 2010, 5:e13208.

69. Levy Y, Caflisch A, Onuchic JN, Wolynes PG: The folding and dimerization of HIV-1 protease: evidence for a stable monomer from simulations. J Mol Biol 2004, 340:67-79.

70. Sharp PM, Hahn BH: The evolution of HIV-1 and the origin of AIDS. Philos Trans R Soc Lond B Biol Sci 2010, 365:2487-2494.

71. Wu TD, Schiffer CA, Gonzales MJ, Taylor J, Kantor R, Chou S, Israelski D, Zolopa AR, Fessel WJ, Shafer RW: Mutation patterns and structural correlates in human immunodeficiency virus type 1 protease following different protease inhibitor treatments. J Virol 2003, 77:4836-4847.

72. Bromberg Y, Rost B: Correlating protein function and stability through the analysis of single amino acid substitutions. BMC Bioinformatics 2009, 10:S8.

73. Gao C, Park MS, Stern HA: Accounting for ligand conformational restriction in calculations of protein-ligand binding affinities. Biophys $J$ 2010, 98:901-910.

74. Heaslet H, Rosenfeld R, Giffin M, Lin YC, Tam K, Torbett BE, Elder JH, McRee $D E$, Stout CD: Conformational flexibility in the flap domains of ligand-free HIV protease. Acta Crystallogr D Biol Crystallogr 2007, 63:866-875.

75. Muzammil S, Armstrong AA, Kang LW, Jakalian A, Bonneau PR, Schmelmer $V$, Amzel LM, Freire E: Unique thermodynamic response of tipranavir to human immunodeficiency virus type 1 protease drug resistance mutations. J Virol 2007, 81:5144-5154

76. Friend J, Parkin N, Liegler T, Martin JN, Deeks SG: Isolated lopinavir resistance after virological rebound of a ritonavir/lopinavir-based regimen. AIDS 2004, 18:1965-1966.

77. Weikl TR, Hemmateenejad B: How conformational changes can affect catalysis, inhibition and drug resistance of enzymes with induced-fit binding mechanism such as the HIV-1 protease. Biochim Biophys Acta 2013, 1834:867-873

78. Centers for Disease Control and Prevention: 1993 revised classification system for HIV infection and expanded surveillance case definition for AIDS among adolescents and adults. MMWR Recomm Rep 1992, 41(RR-17):1-19.

doi:10.1186/1471-2105-15-72

Cite this article as: Mata-Munguía et al:: Natural polymorphisms and unusual mutations in HIV-1 protease with potential antiretroviral resistance: a bioinformatic analysis. BMC Bioinformatics 2014 15:72

\section{Submit your next manuscript to BioMed Central and take full advantage of:}

- Convenient online submission

- Thorough peer review

- No space constraints or color figure charges

- Immediate publication on acceptance

- Inclusion in PubMed, CAS, Scopus and Google Scholar

- Research which is freely available for redistribution

Submit your manuscript at www.biomedcentral.com/submit
C Biomed Central 